\title{
Why nebulise for more than five minutes?
}

\author{
C O'CALlAGHAN, ${ }^{*}$ A R CLARK, $\dagger$ AND A D MILNER*
}

${ }^{*}$ University Hospital, Nottingham, and †Fisons, Loughborough

SUMmaRY The output of the drug and the particle size produced by various nebulisers were assessed, and sensible nebulisation times for sodium cromoglycate calculated. Three of the four nebuliser systems tested produced over $80 \%$ of total drug output within the first five minutes of nebulisation. We suggest that five minutes is an optimum nebulisation time for sodium cromoglycate using these nebuliser combinations.

Nebulisation treatment can upset both child and parent, especially when it is prolonged. Parents frequently report spending up to 20 minutes nebulising a $2 \mathrm{ml}$ charge of sodium cromoglycate. As evaporation makes it impossible to determine output of the drug directly from weight loss of the nebuliser chamber, we have used a multistage liquid impinger to determine output of the drug and aerosol particle size. This has enabled us to suggest an optimum nebulisation time for sodium cromoglycate using the nebuliser combinations available in our department.

\section{Methods}

A multistage liquid impinger as described by May, ${ }^{1}$ and later modified by Bell, ${ }^{2}$ was used to assess the aerodynamic particle size distribution of the aerosol clouds. The device consist of a 'throat' that contains a right angle bend (to simulate the oropharynx) and four impaction stages. Stages 1,2 , and 3 consists of impaction jets together with sintered glass collecting discs. Water is placed in each stage to keep the upper surfaces of the collection discs moist. The fourth stage consists of a narrow jet aimed at the base of the collection chamber.

The impinger had been calibrated by sampling an aerosol of dibutyl phthalate droplets that had been sized by a reference impactor (Cassella impactor). A $50 \%$ cut off diameter was derived for each stage of the device and was expressed in terms of aerodynamic diameter. The aerodynamic diameter of a droplet is the diameter of a unit density spherical particle with the same settling velocity as the droplet in question.

The impinger was assembled as shown (figure) and a vacuum pump used to establish a flow rate of $60 \mathrm{l} /$ minute through the device. The flow rate was adjusted by a pressure relief valve and was measured with a gas flow meter. Two $\mathrm{ml}$ of a $1 \%$ sodium cromoglycate solution was put into the reservoir of the nebuliser chamber with a pipette. The nebuliser chamber was fixed so that the mouthpiece was central and about $2 \mathrm{~mm}$ from the 'throat' of the impinger before nebulisation.

The drug output characteristics from four of each of the following nebulisers run for periods of 5, 10 , and 15 minutes were determined: Pari Inhalierboy; Novair compressor with Cirrhus nebuliser chamber (Intersurgical Ltd); Medix Traveller (System B) (Medix Ltd); and the Nebupump compressor (Corri-Med Ltd) with Unicorn nebuliser chamber (Medic Aid Ltd).

After nebulisation, the various stages of the impinger were washed out quantitatively using distilled water into $100 \mathrm{ml}$ volumetric flasks. The amount of anhydrous sodium cromoglycate was assayed spectrophotometrically using a wavelength of $356 \mathrm{~nm}$. The spectrophotometer had previously been calibrated using solutions of known concentrations of sodium cromoglycate. The absorbance for a $1 \%$ solution using a $1 \mathrm{~cm}$ silica curvette was measured as 166 . The weight loss during nebulisation was calculated by weighing before and after nebulisation. The volumetric flow rate of air through the nebuliser was measured in a separate experiment by connecting a rotameter upstream of the nebuliser after sealing the nebuliser to prevent leaks.

Average nebulisation rate $(\mathrm{N})$ was calculated as: $\mathrm{N}=\mathrm{M} / \mathrm{Co} \times \mathrm{t}$, where $\mathrm{M}=$ mass of sodium cromoglycate in the nebulised cloud, $\mathrm{Co}=$ initial concentra- 


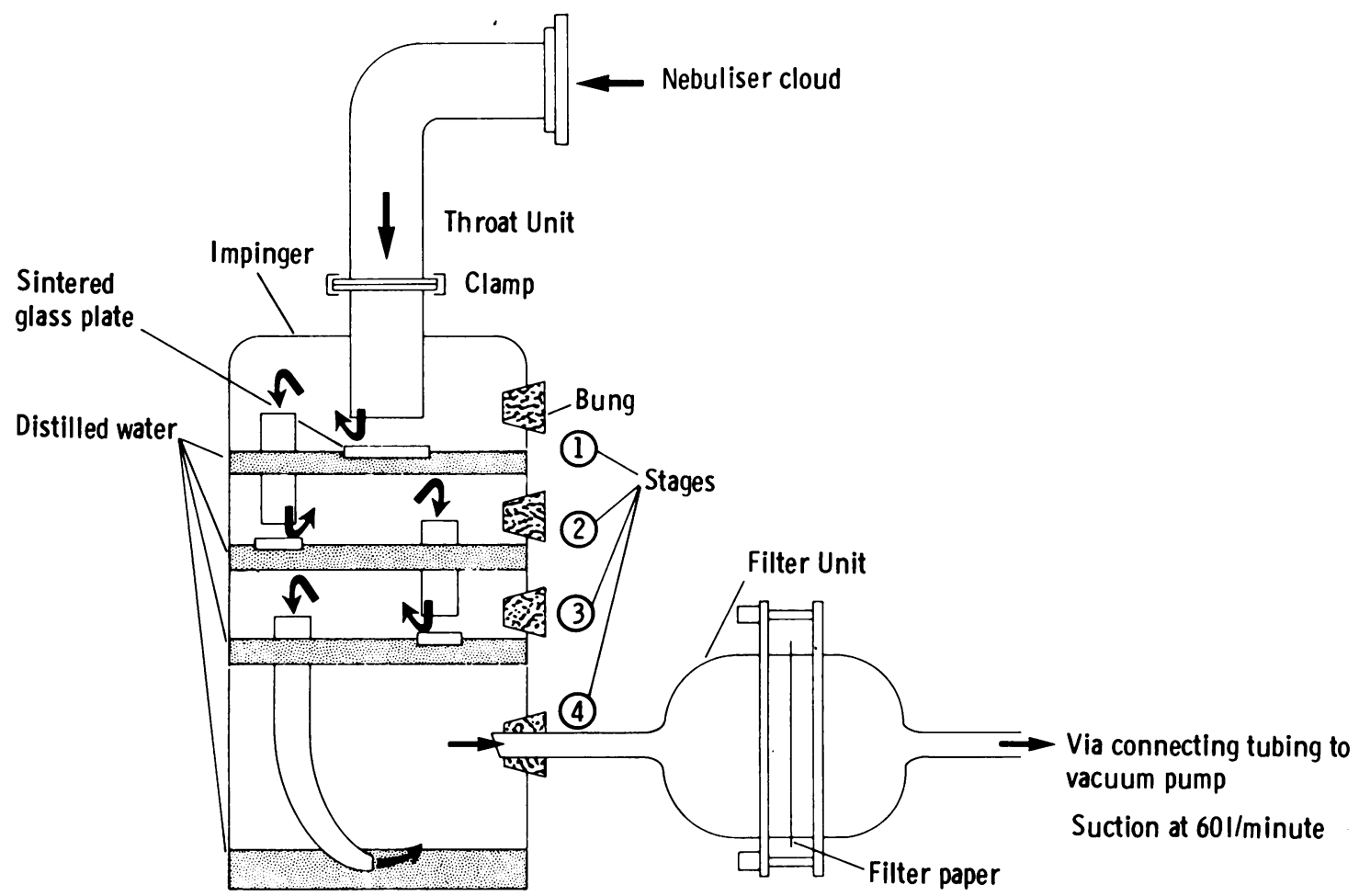

Figure Diagram of multistage liquid impinger. The aerosol cloud is sucked through the device at 60 l/minute. Larger particles impact on the upper stages, smaller ones on the lower stages. The solution can then be assayed in individual stages to determine the amount of drug present in specific particle size ranges.

tion of sodium cromoglycate in reservoir solution, and $\mathrm{t}=$ time (minutes).

The average evaporation rate was calculated by subtracting the nebulisation rate from the rate of weight loss.

Using the data acquired from the Multistage impinger together with the $50 \%$ cut off diameters for each stage of the device, a plot of aerodynamic size against cumulative percentage undersize was constructed. From this graph the following measurements were calculated: mass median aerodynamic diameter, which is the diameter of droplets such that half of the aerosol mass is contained in smaller droplets and half in larger droplets, and the geometric standard deviation, which is the ratio of $84.1 \%$ diameter to the $50 \%$ (mass median aerodynamic diameter) diameter; the value of the geometric standard deviation is a measure of width of the droplet distribution. The percentage of the aerosol mass contained in droplets of less than $4.4 \mu \mathrm{m}$ was also calculated.

\section{Results}

The mean airflow rate downstream of the nebuliser, average nebulisation rate, and average rate of weight loss caused by evaporation are shown in table 1 . Between $20 \%$ (Novair compressor with Cirrhus nebuliser chamber) and $50 \%$ (Medix traveller with Chamber B) of the total weight loss during nebulisation is caused by evaporation.

The drug output after various times of nebulisation, the mass median aerodynamic diameter, and the geometric standard deviation of the four types of nebuliser are shown in table 2. When using the Pari Inhalierboy, Novair compressor and Cirrhus nebuliser chamber, and Medix traveller and Chamber B, over $80 \%$ of the drug was delivered in the first five minutes of nebulisation. The Nebupump compressor in combination with the Unicorn chamber had a much slower output-less than $50 \%$ at five minutes.

Although the Pari Inhalierboy had the greatest 
Table 1 Air flow rate, nebulisation rate, and rate of weight loss caused by evaporation for four commonly used nebulisers: four of each type were tested. Results were obtained using a fill volume of $2 \mathrm{ml}$ of a $1 \%$ sodium cromoglycate solution. Figures are given as mean (SD)

\begin{tabular}{|c|c|c|c|}
\hline & $\begin{array}{l}\text { Mean air flow rate } \\
\text { downstream of nebuliser } \\
(\text { l/min })\end{array}$ & $\begin{array}{l}\text { Average } \\
\text { nebulisation } \\
\text { rate }(\mathrm{ml} / \mathrm{min})\end{array}$ & $\begin{array}{l}\text { Average rate of } \\
\text { weight loss caused by } \\
\text { evaporation }(\mathrm{ml} / \mathrm{min})\end{array}$ \\
\hline Pari Inhalierboy & $4 \cdot 1(0 \cdot 3)$ & $0.18 \quad(0.02)$ & $0.09(0.003)$ \\
\hline Novair Compressor with Cirrhus nebuliser chamber & $5 \quad(0 \cdot 5)$ & $0 \cdot 14 \quad(0 \cdot 2)$ & $0.04(0.008)$ \\
\hline Medix Traveller with Chamber B & $6 \quad(0 \cdot 3)$ & $0.08 \quad(0 \cdot 002)$ & $0.08(0 \cdot 008)$ \\
\hline Nebupump Compressor with Unicorn nebuliser chamber & $3 \cdot 2(0 \cdot 3)$ & $0.063(0.005)$ & $0.04(0.003)$ \\
\hline
\end{tabular}

Table 2 Drug output, mass median aerodynamic diameter, and geometric standard deviation for four commonly used nebulisers: four of each type were tested. Figures are given as mean (SD)

\begin{tabular}{|c|c|c|c|c|c|c|}
\hline & \multicolumn{3}{|c|}{ Total output of sodium cromoglycate (mg) } & \multirow{2}{*}{$\begin{array}{l}\text { Percentage } \\
\text { of drug } \\
\text { contained } \\
\text { in particles } \\
<4.4 \mu \mathrm{m}\end{array}$} & \multirow{2}{*}{$\begin{array}{l}\text { Mass median } \\
\text { aerodynamic } \\
\text { diameter } \\
(\mu \mathrm{m})\end{array}$} & \multirow{2}{*}{$\begin{array}{l}\text { Geometric } \\
\text { standard } \\
\text { deviation }\end{array}$} \\
\hline & At $5 \mathrm{~min}$ & At $10 \mathrm{~min}$ & At $15 \mathrm{~min}$ & & & \\
\hline $\begin{array}{l}\text { Pari Inhalierboy } \\
\text { Novair Compressor with }\end{array}$ & $9 \cdot 2 \quad(0.32)$ & $9 \cdot 35(0.54)$ & $9 \cdot 38(0 \cdot 5)$ & 40 & $6 \cdot 1$ & $2 \cdot 13$ \\
\hline $\begin{array}{l}\text { Cirrhus nebuliser chamber } \\
\text { Medix Traveller with }\end{array}$ & $7 \cdot 1 \quad(0 \cdot 47)$ & $8.4 \quad(0 \cdot 61)$ & $8 \cdot 8 \quad(0 \cdot 6)$ & $84 \cdot 5$ & $2 \cdot 0$ & $2 \cdot 2$ \\
\hline $\begin{array}{l}\text { Chamber B } \\
\text { Nebupump compressor with }\end{array}$ & $7 \cdot 5 \quad(0 \cdot 45)$ & $8 \cdot 15(0.49)$ & $8 \cdot 25(0 \cdot 5)$ & $79 \cdot 8$ & $2 \cdot 3$ & $2 \cdot 34$ \\
\hline Unicorn nebuliser chamber & $3 \cdot 13(0 \cdot 4)$ & $6 \cdot 1 \quad(0 \cdot 42)$ & $7 \cdot 9 \quad(0.45)$ & $82 \cdot 6$ & $2 \cdot 6$ & 3.07 \\
\hline
\end{tabular}

output at five minutes its mass median aerodynamic diameter was $6 \cdot 1 \mu \mathrm{m}$, compared with one of 2-2.6 $\mu \mathrm{m}$ for the other combinations.

\section{Discussion}

We have shown that in three of our nebulisers-the Pari Inhalierboy, Novair, and Medix Traveller, over $84 \%$ of the total drug delivery from a unit dose charge occurs within the first five minutes. We now advice nebulisation for five minutes only, thus improving compliance. The Nebupump, however, with a slow delivery rate, delivered $3.13 \mathrm{mg}$ of sodium cromoglycate during the first five minutes, and doubled this over the next five minutes, to deliver a total of $6.05 \mathrm{mg}$ during the 10 minute period. This prolonged duration of delivery makes it less attractive for paediatric use. The Nebupump compressor produces low flow rate through the nebuliser chamber compared with the other compressor, which is the reason for the slow output. In separate studies the Unicorn chamber performed as well as the Cirrhus chamber and Chamber B when driven by a similar compressor (unpublished observations).

It is important to explain to parents that effective nebulisation finishes while there are still droplets visible in the nebuliser chamber. Parents are often found struggling to hold the facemask to their child's face for up to 30 minutes until these droplets finally evaporate.

Droplets of more than $8 \mu \mathrm{m}$ tend to be captured in the oropharnyx of adults, ${ }^{3}$ while droplets of less than $5 \mu \mathrm{m}$ are considered ideal for penetration into the lungs. ${ }^{4}$ In young children the airways are smaller and it is possible that the optimal droplet diameter is even less, especially in infancy when nose breathing may predominate.

It was interesting that the mass median aerodynamic diameter was similar for all of the nebulisers, except the Pari Inhalierboy, which produced an aerosol with a much larger diameter. Thus although the Pari Inhalierboy produces the most drug at five minutes, many of the particles produced may well be too large to enter the respiratory tract, especially in a young child. In theory therefore it may deliver less drug to the lungs than the Novair and Medix nebulisers.

Using a Multistage liquid impinger it is possible to separate aerosol droplets into various fractions depending on their aerodynamic size. The quantity of sodium cromoglycate in each fraction can be determined using a spectrophotometric assay. Each test took under two hours to do. 
This well established method offers a way of defining the drug output and particle size distribution of commonly used nebulisers and aerosols, which may provide useful information when interpreting trials of nebulised drugs. It is also possible to work out the amount of drug in particles less than a particular size range-for example, the amount of drug in particles less than $1 \mu \mathrm{m}$, or less than $2 \mu \mathrm{m}$, and so on; various nebulisers and nebuliser solutions could easily be assessed using this system. This may help to suggest sensible nebulisation times for the equipment and drug used. Newman et al have shown that by increasing the volume fill by adding more diluent, a greater proportion of the original dose may be released. ${ }^{5}$ This would considerably increase the nebulisation time. In this study we have only considered the recommended dose.

It is clear from the results that an appreciable amount of weight loss from the nebuliser is from evaporation. Thus weight loss cannot be used as a method of measuring drug output.

\section{References}

${ }^{1}$ May KR. Multi-stage liquid impinger. Bacteriological Reviews 1966;30:559-70.

2 Bell JH, Brown K, Glasby J. Variation in delivery of isoprenaline from various pressurised inhalers. J Pharm Pharmacol 1973;25:(suppl) 32-6.

${ }^{3}$ Swift DL. Aerosols and humidity therapy. Am Rev Respir Dis 1980;122:71-7.

4 Clay MG, Pavia D, Clarke SW. Effect of aerosol particle size on bronchodilation with nebulised terbutaline in asthmatic subjects. Thorax 1986;41:364-8.

5 Newman SP, Pellow PGD, Clay MM, Clarke WC. Evaluation of jet nebulisers for use with gentamicin solution. Thorax 1985;40:671-6.

Correspondence to Dr C O'Callaghan, Department of Paediatrics, University Hospital, Queen's Medical Centre, Nottingham NG7 2UH

Accepted 11 April 1989 